OPEN ACCESS

Edited by:

Amalia Zucaro

Italian National Agency for New Technologies, Energy and Sustainable Economic Development (ENEA), Italy

Reviewed by:

Štefan Bojnec,

University of Primorska, Slovenia

Marco Casazza

University of Salerno, Italy

${ }^{*}$ Correspondence: Kristin Floress kristin.m.floress@usda.gov

Specialty section This article was submitted to Urban Resource Management, a section of the journal Frontiers in Sustainable Cities

Received: 22 July 2021 Accepted: 03 February 2022 Published: 07 March 2022

Citation:

Floress K and Cohen A (2022)

Pandemic-era Participation in Public Lands Governance: Lessons From the

USDA Forest Service. Front. Sustain. Cities 4:745727. doi: 10.3389/frsc.2022.745727

\section{Pandemic-era Participation in Public Lands Governance: Lessons From the USDA Forest Service}

\author{
Kristin Floress $^{1 *}$ and Alice Cohen ${ }^{2}$ \\ ${ }^{1}$ Northern Research Station, United States Department of Agriculture Forest Service, Evanston, IL, United States, ${ }^{2}$ National \\ Forests in North Carolina, United States Department of Agriculture Forest Service, Asheville, NC, United States
}

Public participation processes influencing National Forest management in the United States have shifted significantly because of the global COVID-19 pandemic. Although the United States Forest Service has used virtual participation tools in the past to support participation, the pandemic was the first time staff had to solely rely on such methods. Using the Trinity of Voice theory concepts of access, standing, and influence, we discuss how each has been and can be impacted by virtual vs. inperson public participation in federal land governance. Lessons are drawn from two peer-to-peer learning sessions among Forest Service staff in Fall 2020 and a case from the National Forests in North Carolina. Virtual participation can broaden access to processes that would primarily have taken place in-person as people were not limited by travel time or distance. Virtual methods may allow for greater use of adaptive technologies and therefore may increase participation access. Web meeting alternatives (e.g., telephone calls) can be used to increase participation access for those without reliable or affordable internet. However, planners trained in facilitating in-person meetings may not have the technical competencies necessary to ensure participants are able to effectively participate during virtual meetings, and misunderstandings that might be easily addressed in face-to-face settings can be more difficult to solve and ground rules for participation ignored more easily during virtual participation. We expect these lessons will support the work of other practitioners interested in supporting access, standing, and influence when designing virtual participation processes.

Keywords: Trinity of Voice, virtual participation, access, standing, influence

\section{INTRODUCTION}

Public participation in national forests and grasslands governance is carried out by the United States Department of Agriculture Forest Service (USDA-FS) in accordance with federal laws and administrative rules and directives impacting the extent to which stakeholders can influence decisions and how decisions are implemented. While numerous engagement frameworks exist (e.g., see Kliskey et al., 2021 review), in this Perspective, we describe the Trinity of Voice theory-and its key participation constructs of access, standing, and influence-and general considerations for supporting these in virtual (not necessarily digital) engagement. We outline investments USDAFS made in developing public participation competencies to achieve participation goals. We draw upon general lessons as well as specific examples from North Carolina National Forests shared 
during two peer-to-peer virtual engagement learning sessions organized by USDA-FS headquarters to discuss how the pandemic accelerated movement toward broadening virtual engagement as well how challenges with doing so were addressed. While this Perspective is not representative of all USDA-FS engagement approaches during the pandemic, it is intended to highlight issues and considerations that apply across contexts.

Public participation processes generally are intended to ensure all groups benefitting from, burdened by, or with any stake or interest in decisions have opportunities to affect the outcomes. Participation is a vital component of well-functioning societies, as evidenced by its presence in the United Nations (UN) Sustainable Development Goals: SDG 16 aims to, among other things, "Ensure responsive, inclusive, participatory, and representative decision-making at all levels," (UN General Assembly, 2015). Numerous approaches can be used to achieve engagement goals ranging from consulting with stakeholders to empowerment or co-ownership (Kliskey et al., 2021), but all require that stakeholders have access, standing, and some degree of influence in the process (Senecah, 2004). Access is the opportunity to not only participate in the process but also "to access sufficient and appropriate support, for instance, education, information, so that [one] can understand the process in an informed, active capacity, not as a reactionary," (Senecah, 2004, p. 23). Generally, stakeholder participation trends have increased access to information (Fusi, 2020) but may not ensure information literacy-the access and skills needed to assess and use information (UN Educational, Scientific and Cultural Organization, 2021). Indeed, UNESCO believes that "...universal access to information is key to building peace, sustainable economic development, and intercultural dialogue," (UN Educational, Scientific and Cultural Organization, 2021). Standing legitimizes stakeholders' perspectives and results from developing processes thoughtfully so once participants have access their opinions, concerns, and knowledge can be expressed and heard (Senecah, 2004). Together, having access and standing support influencing outcomes. Senecah (2004) states influence "...means that my ideas have been respectfully considered along with those of other stakeholders and... I was part of the process that, for example, determined decision criteria and measured alternatives against it," (Senecah, 2004 p. 25). Influence is essentially synonymous with the definition of, "...power as the capacity to affect outcomes ("power to")," (Beland, 2010, p. 146). Developing engagement processes that support access, standing, and influence is difficult in the best of conditions and more so during times of social upheaval.

Twenty years prior to the COVID-19 pandemic, Coleman and Gøtze (2001) wrote, "two convergent developments... are likely to have a profound effect upon the future shape of democracy,": the first they noted was that it would be difficult to avoid governance crises without addressing inadequacies in how the public are engaged in governance (in other words, access, standing, and influence), and the second was the rise of digital engagement. Digital engagement-in this case, public participation in formal governance processes-had then and continues to have problems that can exacerbate inequalities in power. One significant problem is physical and resource limitations on access: high-speed internet access, necessary skills to use online platforms that enable participation in synchronous activities and discussion boards, as well as access to library and other resources that provide supports needed to fully participate. Participation processes may be designed for "the general public, sometimes the interested public and sometimes smaller circles of representatives of key stakeholder groups," (Quick and Bryson, 2016), and digital access issues have various levels of impact dependent upon who the process is intended to reach.

\section{USDA FOREST SERVICE AND PUBLIC PARTICIPATION}

\section{Investments in Participation Competence}

Prior to the pandemic, USDA-FS had worked toward strengthening public participation in land management planning - the process that sets the broad, strategic direction for a particular national forest or grassland (e.g., Dockry, 2015). The 2012 Planning Rule (36 CFR \$219.4) and associated internal operations procedures altered the timing of involvement by requiring public engagement early and often in developing land management plans rather than relying primarily on public comment on drafted plans as is typical with many regulatory processes (e.g., OECD, 2021a). During land management planning USDA-FS encourages participation by all interested at local, regional, and national levels-including agencies at all levels of governance-as well as federally recognized Indian Tribes or Native Corporations, youth, and underserved populations (Executive Order 13175 of November 6, 2000). ${ }^{1}$ To support forests and grasslands with this work, the agency invested in resources such as: an institution-wide International Association for Public Participation (IAP2) membership; timely trainings and peer networks; and various resources linked to the IAP2 participation spectrum. The USDA-FS uses IAP2 resources to design engagement processes that are appropriate for the type of project/decision and goals for public involvement. For example, sharing information on an already planned prescribed fire requires informing stakeholders but stakeholders have no further impact on the decision once the planning process concludes. Collaboration (not control or co-management) used during land management planning is the highest level of influence stakeholders may have on any decision given USDA-FS by law must retain decision space for its resource management decisions. Support from USDA-FS collaboration specialists is available for individual forests and in agency headquarters to provide to develop tools, templates, and a community of practice to enhance participation competencies of USDA-FS staff. Public engagement specialists

\footnotetext{
${ }^{1}$ The emphasis the 2012 Planning Rule placed on engaging Indian Tribes is in addition to the long-standing government-to-government formal consultation with federally recognized Indian Tribes that is required and an important part of federal decision making that may affect Tribal lands, resources or areas of historic significance-see Executive Order 13175.
} 
fulfill another key function: they allow other resource specialists to use their time focusing on their area of expertise rather than trying to learn about and facilitate engagement processes, and this results in higher quality technical products as well as participation processes. Though the 2012 Planning Rule is specific to the land and resource management plans that are periodically revised or amended, the participation resources are developed and available for all future participatory activities a forest or grassland may undertake-often in partnership with groups who help to share information, convene stakeholders, and hold the agency accountable-setting the foundational groundwork for on-going collaborative projects and efforts in implementation of the plan. For example, stakeholders typically participate in on-going project activities related to place-based forest restoration, fuels mitigation, and trail building projects.

The 2012 Planning Rule and subsequent adoption of IAP2's spectrum of participation has led to many USDA-FS employees becoming conversant in tools available to "do" public participation, but it is important to explicitly consider how different choices alter the access, standing, and influence of stakeholders. Engagement efforts that aim to equitably govern the use and management of national forests and grasslands are based in principles of democratic participation, and much of this literature, as Quick and Bryson (2016) note, has evolved from Arnstein's (1969) seminal work that described "citizen engagement [as] a categorical term for citizen power. It is the redistribution of power that enables the have-not citizens, presently excluded from the political and economic processes, to be deliberately included in the future," (Arnstein, 1969). While much of public agencies' engagement work is not described as righting societal power imbalances the difficult work of ensuring the maximum number of groups, individuals, and interests have access to the resources necessary to participate meaningfully serves to highlight that any process can deepen or lessen those imbalances. Further, the "Alienation Index," which has been included in the Harris Poll of US residents since 1966 , indicates that $68 \%$ of residents "believe that what they think does not count very much anymore," (Birth and Simon, 2016). As Coleman and Gøtze (2001) note, during the Vietnam War (around the same time Arnstein wrote about ladders of participation) only $1 / 3$ of those polled agreed with that statement. The USDA-FS, to fulfill its obligations to the public, grapples with who is participating, who is not, and how processes can be designed to support public confidence in governance of public lands.

\section{Who Are Considered Stakeholders?}

The USDA-FS manages 174 national forests and grasslands that comprise 192.9 million of the 640 million acres of federal land in the United States (Vincent et al., 2020). Nearly half of the US population lives within 50 miles of these lands: drawing a 50 mile buffer around each national forest places nearly the entire country that falls within the mountain and pacific time zones within those bounds as well as significant portions of the south, southeast, and upper Midwest United States (e.g., English et al., 2015). The majority of visits to national forests are from those who travel $<100$ miles and visitation during the pandemic has increased three-fold over normal rates in some cases (e.g., North Carolina April 72020 media release). In 2010, there were 58 national forests and grasslands that had nearby populations of over 1 million people and several with more than five million nearby residents (English et al., 2015). Further, monitoring data suggest that recreational use of Forest Service sites is largely by those who identify as white, even in racially diverse areas. For example, $96.1 \%$ of Midewin National Tallgrass Prairie visitors in 2018 were white (USDA Forest Service, 2018), though the Prairie is within and adjacent to counties and the city of Chicago that have some of the most racially diverse populations in the nation (Olson, 2014). Of course, USDA-FS stakeholders are not limited to nearby residents, groups, and interests, but comparing who lives near vs. who visits national forest lands can be useful for thinking about who may or may not consider themselves to be stakeholders in decision processes and especially how engagement might be designed to increase participation. The proximity of USDA-FS lands to a significant portion of US residents serves as a reminder that stakeholders are inclusive of people who reside in large and small cities, suburbs, and exurbs as well as rural areas, and who have varying access to resources that enable them to participate in decision processes.

\section{ACCESS, STANDING, AND INFLUENCE IN NORTH CAROLINA NATIONAL FOREST DECISIONS}

\section{Trinity of Voice: Efforts to Support Access}

The USDA-FS, in its efforts to increase access to information and stakeholders' ability to inform decisions, expanded its use of websites and asynchronous tools to share information that would allow stakeholders to participate in planning meetings prior to the pandemic, but accelerated these efforts in 2020 to account for lost face-to-face engagement opportunities. For example, National Forests in North Carolina were updating a 1987 land management plan and in the middle of their public participation process when the global pandemic hit. Their planning process had already included over 300 faceto-face meetings with varying audiences, sizes, and formats over several years. They had utilized some social and online communication tools, though significantly increased use of these due to COVID-19. The Forest website included five virtual stations offering information on the land management planning process and topics, simulating formerly planned open house public gatherings that would have been offered prepandemic (Box 1). Videos, a Reader's Guide, story maps, and an overview of information were developed or modified to provide broader access to the essential materials facilitating participation in the planning process. Planned engagement activities were redesigned to address virtual-only options for interaction during the pandemic. For example, six of seven in-person deepdive discussions were transitioned to the web. This required redesigning the scheduling and format of the information sharing and interaction parts of the webinar, with greater consideration 
BOX 1 | Planned in-person and alternative virtual engagement processes, North Carolina National Forests

\section{Open Houses}

Pre-pandemic: Seven in-person Open House events planned. One was held and included 40 participants.

Post-pandemic: Converted website to approximate an Open House format with 7 stations including videos, StoryMaps, webinar recordings, documents and other resources. The link was shared with a listserv of 15,000, plus general social media hits on

various pages.

Station 1: Getting started

Station 2: Digging into the proposed plan

Station 3: Exploring the influence of management

Station 4: Exploring unique topics

Station 5: Comment consideration and Next Steps

Four Q\&A conference call sessions were offered to the public to address connectivity issues in rural communities. There were 10-33

participants in each call, depending on the time of day and day of the week. There was more attendance during evening calls.

Two Q\&A conference calls were offered to county staff and representatives to address connectivity issues in rural communities and provide an opportunity to hear local community concerns. There were 32 participants representing 18 counties.

Pre-pandemic: Seven Deep Dive discussion planned upon request from collaborators. One held with 15 collaborators participating.

Post-pandemic:

Shifted to pre-recorded presentations posted to the website.

Solicited written questions, then posted Q\&A content to the website.

The link was shared with a listserv of 15,000, plus general social media hits on various pages.

Pre-pandemic: An online comment analysis and response application was the primary email option for submitting comments and

otherwise contacting the planning staff.

Post-pandemic: The forest plan revision internet inbox, normally rarely utilized, was a significant tool for communication at

times during the planning process. We received more than 1,900 emails in the project inbox that were manually handled by staff.

for the progression of how and when the information would be received.

In the absence of personal interaction and the opportunity to clarify issues relating to the interdependence of topics, there was greater potential for collaborative process derailment. To address differences in access to adequate broadband and technology, the Forest worked directly with county and regional representatives to identify best options. As a result, the Forest offered and facilitated engagement opportunities that solely relied on phones rather than computer hardware, software, and strong internet connections. The Forest's supervisory leaders participated in each call to communicate directly with stakeholders, rather than the typical in-person procedure where a small subset would attend each open house. Facilitation guides were drafted and roles assigned and outlined in advance, and during calls an internal online messaging channel was utilized by all Forest leaders for internal communication to assure smooth facilitation. Numerous communications were required during each virtual presentation offered to county staff and officials. The Forest also created and monitored an email account to facilitate directly receiving questions in advance or in lieu of attending the call. Numerous engagement opportunities were also designed to address diverse and inclusive audiences. For example, engagement opportunities were offered to new audiences on different days and at different times to address common work and family time constraints and numerous reminders were sent through USDA-FS and partner channels to reach the broadest audiences. Additional informational/educational videos and materials were created and added to the website for greater public access to materials that had been slated to be delivered, hardcopy, to local county offices and libraries. Staff spent many hours communicating with collaborators to assure clear communication was taking place in the absence of faceto-face meetings that would have allowed for more immediate and clarifying reactions and interactions. For example, 12 phone conversations took place to clarify one misunderstanding that could have been resolved during a face-to-face meeting. It is generally accepted by the Forest and partners that the outreach efforts were a success as evidenced by the broad acceptance and support of the draft materials released. Where staff perceived there would typically be significant negative reaction in the media and organizational communication channels on a number of hot button topics, there was not. Collaborators broadly supported the process and continue to work together to resolve issues.

However, the ready availability of information does not mean all stakeholders have equitable access. Even if all participants have access to necessary equipment (personal technology, computers) they may not have access to the internet or reliable cell service. Wheeler (2020) notes that availability (in rural areas) and affordability (in urban and rural areas) of internet services perpetuate inequalities that limit economic and social participation. Chiou and Tucker (2020) state that, “...the combination of high-income and highinternet diffusion appears to be a large driver in observed inequality," (p. 3). The US Public Participation Playbook, an open government initiative of the Obama administration, offers a number of suggestions to "design for inclusiveness," including accessibility for those with disabilities and who speak languages other than English as well as providing physical and digital versions of materials needed to participate. Even the best efforts, however, may not be able to overcome participation access issues without equitable access to digital resources. For example, $25 \%$ of stakeholders were unable 
to be reached digitally for inclusion in energy research engagement processes (Susser et al., 2021). While Senecah noted in 2004 that, "Access is easy to provide. Standing is far trickier," (p. 24), we suggest that access may be easier to ensure than standing, but the "digital chasm" during a global pandemic is nearly impossible to close to ensure participation opportunities for those without computer technologies in their homes. Further, ensuring access also requires ensuring that conveners have the software, platform, and skills necessary to offer digital information and participation opportunities, and potential participants have corresponding skills that allow them to participate.

Some benefits of virtual engagement noted by USDA-FS staff include the broadening of participation opportunities for those who otherwise may not be able to travel to meeting locations due to distance, time, and expense constraints. If we consider even the people within 50 miles of a given forest or grassland, more than 2 hours away from jobs or home may be required just for travel to a meeting that is held on or near the site. Specific software programs being used for virtual engagement increase access for certain participants; for instance, closed captioning provides access for those with hearing impairments and recordings allow those who are unable to make some meetings to be able to review a meeting in its entirety rather than just notes. Facilitating active conversations with interested stakeholders via phone allowed for better storytelling, context and valuable input than through web-based feedback forms. And innovative, visual materials remain readily available for those seeking to reference them at a later date.

\section{Trinity of Voice: Efforts to Support Standing}

Once the public has access to a process and necessary information, a process must be designed that supports "good" participation. A short list of characteristics of good participation processes includes skilled facilitation that allows all voices to be respectfully and empathetically heard, clearly defined bounds on time investment expectations, a physical arrangement that does not suggest or reinforce power structures, and opportunities for two-way communication and debate (Senecah, 2004). Design to ensure and increase standing is relevant for both synchronous (activities taking place at a specific point in time, like a virtual public meeting) and asynchronous activities (those not requiring participation at a specific point in time, but on one's own schedule with an end-date) like engaging with material and submitting comments and ideas to a virtual workspace. Asynchronous activities may be somewhat easier to administer but may not be as useful for brainstorming, collaboration, or deliberation.

The skills needed to support standing are extensive: competency in traditional meeting facilitation skills (e.g., designing breakout group activities), technical skills to operate systems behind the scenes and manage multiple digital documents that may be referenced throughout a meeting, as well as the digital savvy to sort potentially hundreds of participants into breakout groups while also moderating those groups for adherence to behavioral guidelines. Participants, too, need technical skills to bolster their standing: knowing the layout of the virtual space, for example how to raise one's hand if that's required for the facilitator to unmute speakers, or how to unmute oneself when they would like to speak. Some USDA-FS staff running these processes have noted that enforcing behavioral guidelines, such as taking turns to speak and avoiding situations where the loudest/most persistent voices receive the majority of the attention, can be more challenging virtually than they are in-person. Other staff, however, feel that online platforms allow conveners controls to prevent such behaviors and lead more balanced and civil calls. The clear behavioral guidelines noted earlier accompanied by protocols for technical support to decide under which circumstances participants should be muted have aided staff leading synchronous activities.

\section{Discussion: What of Influence?}

Influence is dependent upon access and standing, and the pandemic has caused shifts in how engagement is structured to support these across a number of institutions and countries (e.g., Mouter et al., 2021; Susser et al., 2021). Attempts to replicate the same activities virtually as are held in person may require additional considerations for digital engagement (for those with internet access), and perhaps lessons from the marketing literature can be used to structure engagement experiences according to the ways individuals prefer to engage with online content instead of (or in addition to) designing involvement based upon best practices in the participation literature. For example, the consumers' online brand related activities (COBRA) continuum (Muntinga et al., 2011), widely applied in the marketing literature, explains three types of online usage: consuming (reading information, passive engagement), contributing (responding to questions/comments, active engagement), and creating (developing new content related to a product or brand). This could be used to support influence by designing experiences that appeal to the ways in which public lands stakeholders enjoy interacting with online content. In contrast to synchronous meetings or calls asynchronous content engagement may provide different, or more, opportunities for stakeholders to collaborate by creating content to which other stakeholders may reply. For example, users could upload pictures and videos-of favorite spots for certain activities, maintenance needs on trails, places in other open spaces that users would love to see-to a national forest's Facebook post requesting such. Two examples of interactive online content that facilitate contributing and creating input are ArcGIS interactive maps and StoryMaps. Both provide visuals and content in an accessible format, more so with the increase in online experience resulting from the COVID-19 pandemic. Stakeholders can identify and reply to specific areas and related management proposals in ways that were previously underutilized and less accessible. Individuals resistant to online formats may find these tools support their desires to offer direct, localized input.

The USDA-FS considers all public comments throughout the land management planning process, including incorporating or otherwise responding to comments within the NEPA process. The 2012 Planning Rule requirements (36 CFR 219.4) and NEPA outline opportunities for and requirements to engage the public. However, federal law dictates the level of decision-making and implementation powers both the agency and the public have, and subsequently the 
agency cannot offer stakeholders (or other Tribal, state, or local governments or governmental agencies) full decisionmaking or implementation power and responsibility (i.e., comanagement). The process of incorporating public input involves internal consideration as well as collaboration with the public to clearly understand and best utilize and incorporate the ideas the public provides. It is difficult to evaluate the level of influence the public has had on decisions over the course of the pandemic that may be different than what would have been achieved during business-asusual planning. However, supporting increased engagement opportunities can lead to additional avenues for information sharing, connections among stakeholders, and potentially increase the likelihood of decision influence within the boundaries of law.

Multiple options for engagement that requires limited participation (e.g., Finland's eParticipation platform, OECD, 2021b) or simple surveys exist already and have been put to use in policy processes-even for setting policies related to reopening options during COVID-19 (e.g., Mouter et al., 2021). Many of these, though, provide public comment windows on draft proposals rather than seek input early enough to influence the direction of a policy or plan. As virtual planning processes and desires to equitably distribute power proliferate, access, standing, and influence will depend upon planners who can skillfully integrate methods that support these goals (e.g., through planning wisdom gained through practice, Flyvbjerg, 2004; Xiang, 2016). We hope this Perspective has provided options and considerations for broadening engagement opportunities to maximize access, standing, and influence during the pandemic and into the future.

\section{REFERENCES}

Arnstein, S. R. (1969). A ladder of citizen participation. J. Am. Institute Plann. 35, 216-224. doi: 10.1080/01944366908977225

Beland, D. (2010). The idea of power and the role of ideas. Politic. Stud. Rev. 8, 145-154. doi: 10.1111/j.1478-9302.2009.00199.x

Birth, A., and Simon, E. (2016). The Harris Poll \#54. July 28, 2016. The Harris Poll.

Chiou, L., and Tucker, C. E. (2020). Social distancing, internet access, and inequality. NBER Working Paper No. w26982. Available online at: https://ssrn. com/abstract=3574446. (Accessed June 30, 2021).

Coleman, S., and Gøtze, J. (2001). Bowling Together: Online Public Engagement in Policy Deliberation. London: Hansard Society.

Dockry, M. J. (2015). Looking back to move forward: collaborative planning to revise the Green Mountain and Finger Lakes National Forests land and resource management plans. Interdisciplin. J. Partnership Stud. 2:101. doi: 10.24926/ijps.v2i1.101

English, D. B. K., Froemke, P., and Hawkos, K. (2015). Paths More Traveled: Predicting Future Recreation Pressures on America's National Forests and Grasslands-A Forests on the Edge report. FS-1034, Washington, DC: US Department of Agriculture, p. 36.

Executive Order 13175 of November 6 (2000). Consultation and coordination with indian tribal governments. Federal Regist. 65, 67249-67252.

Flyvbjerg, B. (2004). Phronetic planning research: Theoretical and methodological reflections. Planning Theory and Practice. 5, 283-306. doi: 10.1080/1464935042000250195

Fusi, F. (2020). When local governments request access to data: power and coordination mechanisms across stakeholders.

\section{DATA AVAILABILITY STATEMENT}

The original contributions presented in the study are included in the article/supplementary material, further inquiries can be directed to the corresponding author.

\section{AUTHOR CONTRIBUTIONS}

KF wrote the first draft and conceived of the initial ideas in this paper with Bradley Kinder and Kenli Kim (see acknowledgments). AC contributed writing to all sections and wrote the North Carolina case example. Both authors contributed to manuscript revision, read, and approved the submitted version.

\section{FUNDING}

This paper was supported by the USDA Forest Service.

\section{ACKNOWLEDGMENTS}

The findings and conclusions in this report are those of the author(s) and should not be construed to represent any official USDA or U.S. Government determination or policy. We are grateful to Bradley Kinder and Kenli Kim for their contributions to early conversations about this paper, to Andrea Bedell-Loucks for her review of an earlier draft, and for the reviewers' helpful comments. We also thank the presenters and participants from two USDA Forest Service peer learning sessions who shared their experiences with virtual engagement methods for public participation during the pandemic.

Public Administr. Rev. 81, 23-27. doi: 10.1111/puar. 13307

Kliskey, A., Williams, P., Griffith, D. L., Dale, V. H., Schelly, C., Marshall, A.M., et al. (2021). Thinking big and thinking small: a conceptual frameworks for best practices in community and stakeholder engagement in food, energy, and water systems. Sustainability 13, 160. doi: 10.3390/su1304 2160

Mouter, N., Hernandez, J. I., and Itten, A. V. (2021). Public participation in crisis policymaking. how 30,000 Dutch citizens advised their government on relazing COVID-19 lockdown measures. PLOS ONE 16, 5. doi: 10.1371/journal.pone.0250614

Muntinga, D. G., Moorman, M., and Smit, E. G. (2011). Introducing COBRAs: Exploring motivations for brand-related social media use. Int. J. Advertising 30, 13-46. doi: 10.2501/IJA-30-1013-046

OECD (2021a). OECD Regulatory Policy Outlook 2021. Policy Brief Chapter 2: Evidence-Based Policy Making and Stakeholder Engagement. Available online at: https://www.oecd.org/gov/regulatory-policy/chapter-two-evidence-basedpolicy-making-and-stakeholder-engagement.pdf (accessed October 28, 2021). OECD (2021b). Better Regulation Practices across the European Union. Chapter 2. Stakeholder engagement across the European Union. Available online at: https://www.oecd-ilibrary.org/sites/dd9b13ad-en/index.html?itemId=/ content/component/dd9b13ad-en. (accessed November 03, 2021).

Olson, R. (2014). U.S. Racial Diversity by County. Available online at: http://www. randalolson.com/2014/04/29/u-s-racial-diversity-by-county/ (accessed April 27, 2021).

Planning Rule (2012). 36 CFR \$219.4. Requirements for Public Participation\$. (accessed July 272012 ). 
Quick, K., and Bryson, J. M. (2016). "Theories of public participation in governance. Ch. 12," in Handbook in Theories of Governance, eds Torbing, J. and Ansell, C (London: Edward Elgar Press).

Senecah, S. L. (2004). "The trinity of voice: The role of practical theory in planning and evaluating the effectiveness of environmental participatory processes. Chapter 1," in Communication and Public Participation in Environmental Decision Making, eds Depoe, S.P., Delicath, J.W. and Elsenbeer, M-F.A. (New York, NY: State University of New York Press).

Susser, D., Ceglarz, A., Stavrakas, V., and Lilliestam, J. (2021). COVID-19 vs. stakeholder engagement: the impact of coronoavirus containment measures on stakeholder involvement in European energy research projects. Open Res. Europe 57, 1-23. doi: 10.12688/openreseurope. 13683.3

UN Educational, Scientific and Cultural Organization. (2021). Access to Information. Available online at: https://en.unesco.org/themes/accessinformation (accessed November 03, 2021].

UN General Assembly. (2015). Transforming our World: The 2030 Agenda for Sustainable Development. Available online at: https://www.un. org/en/development/desa/population/migration/generalassembly/docs/ globalcompact/A_RES_70_1_E.pdf

USDA Forest Service (2018). Visitor Use Report, Midewin National Tallgrass Prairie. National Visitor Use Monitoring Program. National Visitor Use Monitoring Results. Available online at: https://apps.fs.usda.gov/nvum/results/A09015. aspx/FY2018 (accessed June 30, 2021).

Vincent, C. H., Hanson, L. A., and Bermejo, L. F. (2020). Federal Land Ownership: Overview and Data. Congressional Research Service Report R42346

Wheeler, T. (2020). 5 steps to get the internet to all Americans: COVID19 and the importance of universal broadband. The Brookings Institution. Available online at: https://www.brookings.edu/research/5-steps-to-get- theinternet-to-all-americans/
Xiang, W. N. (2016). Ecophrenesis: the ecological practical wisdom for and from ecological practice. Landscape Urban Plann. 155, 53-60. doi: 10.1016/j.landurbplan.2016.07.005

Conflict of Interest: KF and AC are employees of the USDA Forest Service which could be construed as a potential conflict of interest. Every reasonable effort was made to ensure that this paper presents factual, unbiased information. Further, the findings and conclusions in this paper are those of the authors and should not be construed to represent any official USDA or U.S. government determination or policy.

The authors declare that the research was conducted in the absence of any commercial or financial relationships that could be construed as a potential conflict of interest.

Publisher's Note: All claims expressed in this article are solely those of the authors and do not necessarily represent those of their affiliated organizations, or those of the publisher, the editors and the reviewers. Any product that may be evaluated in this article, or claim that may be made by its manufacturer, is not guaranteed or endorsed by the publisher.

Copyright (C) 2022 Floress and Cohen. This is an open-access article distributed under the terms of the Creative Commons Attribution License (CC BY). The use, distribution or reproduction in other forums is permitted, provided the original author(s) and the copyright owner(s) are credited and that the original publication in this journal is cited, in accordance with accepted academic practice. No use, distribution or reproduction is permitted which does not comply with these terms. 